\title{
La Enseñanza de la Arquitectura en Chile
}

a formación de arquitectos en nuestro país Le remonta a las acciones que iniciara a partir de 1780 el primer arquitecto contratado por el gobierno de la época; hablamos de Joaquín Toesca, de origen italiano y parte de los profesionales que se trasladan con las cortes desde el Reino de Nápoles a Madrid, una vez que Carlos III es elevado a Rey de España en 1759 quien es reconocido como el rey de la \|lustración española.

La necesidad de un arquitecto en la lejana Capitanía de Chile se conjugaba con una falta de materiales y mano de obra de calidad y competente, situación que el arquitecto resuelve magistralmente al congregar a diario a albañiles y jornales interesados en la buena fábrica de sus obras. A ellos se sumaban jóvenes talentos que se convertirían después en los seguidores de su quehacer -en conjunto con los ingenieros militares-, sin tener títulos de arquitecto. Tal vez esta condición primera de la formación en la disciplina marcará el devenir de esta en nuestra nación.

El proceso de la Independencia y los consiguientes años de consolidación del
Estado de Chile pasaron sin arquitectos. Los ingenieros militares que cumplían aquellas funciones volvieron a España tras la guerra de independencia; en tanto que a partir de la muerte de Toesca, en 1799, el país dejó de contar con arquitectos.

Así surge la necesidad de arquitectos o quienes se hicieran profesionalmente cargo de la reparación y edificación de obras a partir de la década de 1830. El país era un un medio que por su escaso desarrollo cultural no lograba comprender la necesidad de contar con arquitectos y no solo capataces o jefes de obra profesionales; de esta forma la preocupación del Estado se concreta en la contratación de un arquitecto de gobierno para sus obras, quien además tendría la misión de iniciar un proceso formativo de nuevos profesionales. Así nos lo señala Encina ["]: "se encargó a Rosales que contratase en Francia un arquitecto competente, y este tuvo la suerte de conseguir que François Brunet Des Baines, a la sazón joven profesional hábil y competente aceptase venir a Chile (...) llegó a Chile en 1849 (...) dirigió la construcción de los mejores edificios particulares que se levantaron en Santiago a mediados del siglo XIX.
Pero a diferencia de Monvoisin se interesó por formar arquitectos chilenos, y sin exageración se le puede llamar el fundador de la arquitectura moderna en Chile".

Es en este contexto que Brunet Des Baines formaliza la creación del "curso de arquitectura" en 1849, el que se impartirá en los niveles superiores del Instituto Nacional, que tras las reformas de 1843, concentraba la educación secundaria en sus cursos iniciales y la superior bajo la tuición de la recién creada Universidad de Chile. Esta situación no hace más que confirmar nuevamente la dificultad de instalar la disciplina arquitectónica en el medio nacional, por cuanto no queda formalmente en la universidad nacional, sino bajo su tuición, siendo a su vez un elemento complementario en la formación de matemáticos o ingenieros. El tratado se publicará en 1853 y será considerado por los estudiosos como el primer tratado de enseñanza de arquitectura en América Latina ${ }^{[2]}$.

La formación en este ambiente difuso habría provocado la falta de interés en la continuidad de los estudios de agrimensores o matemáticos, titulándose recién el primer arquitecto chileno,

\footnotetext{
Profesor Asociado IHP

F. A. Encina. "Historia de Chile". Tomo XXIV. Editorial Lord Cochrane, 1984; p. 91

Ramón Gutiérrez. "Arquitectura y Urbanismo en Iberoamérica". Ediciones Cátedra, 1992.
} 
Ricardo Brown, en 1862. A pesar de lo anterior, reconoce Encina ${ }^{[3]}$ la instalación de la cátedra de arquitectura en 1849: "figura en las historias tradicionales con el pomposo título de Fundación de la Escuela de Arquitectura".

Visto lo anterior, hablar sobre la primera Escuela de Arquitectura en Chile nos puede llevar a equívocos. Si bien la Escuela de Arquitectura de la Universidad Católica se funda en 1894 y la de nuestra Universidad en 1896, no es menos cierto que más allá de los nombres y formas pedagógicas que se esgriman, la formación de arquitectos en el país nace con el curso de arquitectura. Este curso que se sumaba a la formación en "los cursos de Ingeniería o Preparatorio de Matemáticas, que, con un programa idéntico al que tenía establecido la Universidad de Chile, capacitaba al alumnado para obtener el título de bachiller en Matemáticas, requisito sine qua non para iniciar la carrera de ingeniería propiamente tal", como refieren Méndez y Ballacey ${ }^{[4]}$ para explicar la forma en que se funda su propia institución en el libro que conmemora los cien años de la creación de la Escuela de Arquitectura de la Universidad Católica.
En consecuencia, podemos señalar que hasta 1894 la formación de arquitectos era una situación complementaria a la formación en ingeniería o matemáticas, fuerza y forma que hasta hoy prima en la formación de los arquitectos de la Universidad de Chile. La creación de una "Escuela de Arquitectura" no hace más que plasmar el natural deseo de Brunet des Baines de dar una formación a los arquitectos en forma integral y autónoma, situación que la Universidad Católica pudo consolidar antes en pos de su tradicional agilidad normativa. Este modelo de escuela será tomado a posteriori por nuestra universidad, tras la reforma del Curso de Arquitectura bajo la tuición del arquitecto francés Emilio Doyere (1896), y que como citan los mismos Méndez y Ballacey, "tras una de las 'periódicas crisis' que sacuden a esta", nuestra escuela.

Como la historia se repite, dentro de una de estas crisis, se decidió tras la última reestructuración de la facultad, crear una escuela única de pregrado el año 2009, transformando la antigua escuela en carrera de arquitectura. Si bien el nombre y las implicancias están a la vista, no puede desconocerse que Ricardo Brown -el primer arquitecto titulado en Chile- fue formado en nuestro "Curso de Arquitectura" y que logra la certificación de arquitecto en 1862, muchos años antes de 1888, fecha en que se funda la Universidad Católica.

Por tanto, al señalarse en medios digitales de la Universidad Católica que "en 1894 se comienza a dictar un curso de arquitectura, que fue el que dio origen a esa disciplina en Chile" ${ }^{[5]}$ es un error, el mismo que se comete en un artículo de reciente edición de la revista DOMUS en que se abordan los 120 años de la escuela de arquitectura de dicha universidad.

La enseñanza de la arquitectura en Chile de manera formal y avalada por las instancias superiores de la nación, se inicia con el curso de arquitectura de Brunet des Baines en 1849, situación que es reconocida y valorada por el historiador de la arquitectura y arquitecto argentino Ramón Gutiérrez, quien señala: "la Escuela de Arquitectura formada en 1849 fue realmente pionera por su estabilidad y logros en Sudamérica. Los anteriores intentos de diversos países fueron prontamente frustrados y dejaron escasas secuelas en relación con la obra de Brunet" ${ }^{\prime[6]}$.

\footnotetext{
[3] Ídem.

"1894-1994 Cien años de Arquitectura en la Universidad Católica". Ediciones ARQ, 1994

Página principal sitio web Universidad Católica. http://www.uc.cl/es/la-universidad/historia

6] Ramón Gutiérrez. "Arquitectura y Urbanismo en Iberoamérica". Ediciones Cátedra, 1992.
} 